\title{
O USO DE MASSA CONGELADA NA PRODUÇÃO DE PÃO
}

\author{
EDSON WATANABE * \\ VERA TOLEDO BENASSI *
}

\begin{abstract}
O artigo apresenta revisão de literatura sobre o uso de massa congelada na produção de pão. São abordados os diferentes tópicos que compõem o assunto, desde a escolha da farinha mais adequada até às condições de forneamento do pão produzido, passando pela formulação e condições de mistura, fermentação, congelamento e descongelamento da massa. Conclui que é difícil esclarecer as questões mais freqüentes sobre 0 assunto, relativas ao melhor tipo de congelamento (criogênico ou mecânico), à fermentação (antes ou depois do congelamento) e às condições de congelamento e de descongelamento (rápido ou lento). Isto porque a literatura disponível trata de massas destinadas à produção dos mais variados tipos de pães e do processo como um todo, o que dificulta a adaptação da tecnologia existente ao pão francês consumido no Brasil.
\end{abstract}

\section{INTRODUÇÃO}

As primeiras tentativas de produção de pão a partir de massa congelada ocorreram na década de 50, nos Estados Unidos. Nesta época, devido à inexistência de equipamentos apropriados, eram utilizados misturadores de cimento e congeladores de sorvete (21). Muito antes (1926), na Áustria, já haviam sido realizados experimentos utilizando baixas temperaturas para o retardamento da etapa de fermentação da massa, numa tentativa de reduzir o trabalho noturno nas padarias (29).

Nas décadas de 50 e 60, o mercado de massa congelada para produção de pão não obteve êxito, por diversas razões, entre as quais a curta vidade-prateleira e o procedimento de preparo do produto, pelo consumidor, muitas vezes inadequado. Entretanto, a partir da década de 70 , nos Estados Unidos, o uso de massa congelada começou a ganhar popularidade com a abertura de novo canal de mercado, ou seja, as

Pesquisadores da Empresa Brasileira de Pesquisa Agropecuária (EMBRAPA), Agroindústria de Alimentos, Rio de Janeiro, RJ. 
padarias das grandes redes de supermercados (31). Ainda nesta mesma década, algumas padarias de pequeno porte consideravam conveniente e econômico o congelamento de porções-reserva de massa, que podiam ser mantidas por alguns dias ou semanas no congelador, para serem então descongeladas, fermentadas e assadas nos horários de maior demanda (23).

O uso de massa congelada veio ao encontro da exigência dos consumidores por pães sempre "frescos", isto é, recém-assados, independentemente do horário da compra $(12,26)$, permitindo, ao mesmo tempo, maior flexibilidade na produção, e diminuindo consideravelmente o trabalho noturno nas padarias (29). Todas estas vantagens fizeram com que $o$ uso da massa congelada começasse a ganhar aceitação por parte da indústria de panificação (15).

As maiores deficiências apontadas para este tipo de produto são: baixo volume $(1,7,10,14)$, estrutura de miolo aberta e mais firme $(4,5,29)$, tempo de fermentação excessivamente longo, qualidade do produto razoável por apenas algumas semanas, isto é, o potencial de panificação da massa decresce substancialmente com o tempo de armazenamento ( 3 , $4,15,22,25,26,31,32$, ) e com os ciclos de congelamento e descongelamento parciais, que podem ocorrer durante a distribuição, transporte e armazenamento do produto $(5,7,16,17,18,20,22)$. Entretanto, devido ao enorme avanço na qualidade dos produtos de panificação, trazidos pelo aprimoramento das formulações, da tecnologia de processo e da metodologia de congelamento (21), assim como dos tipos de levedura $(8,24,25)$, dos tipos de farinha $(18,25)$, de agentes oxidantes $(15,17)$ e condicionadores $(7,22)$, tais desvantagens estão sendo minimizadas.

Com o aumento do número de padarias instaladas nas redes de supermercados, a produção de pão a partir de massa congelada aumentou muito nos últimos anos $(26,30,32)$. Segundo BERGLUND et al. (3) mais de $50 \%$ destas padarias, nos Estados Unidos, fazem uso de massa congelada. Em grande parte dos casos, o pão é produzido na unidade central e comercializado em diversos pontos de venda, os chamados "hot spots".

Embora já se encontre, no Brasil, equipamentos para a produção deste tipo de produto (câmaras de congelamento rápido, câmaras que permitem o descongelamento e a fermentação programável com controle da umidade relativa), tal tecnologia ainda não foi adaptada à produção do pão francês, que é justamente o tipo de pão com maior tradição e aceitação por parte dos consumidores. Pode-se encontrar extensa bibliografia a respeito de massa congelada, mas esta raramente é específica para pão francês. Geralmente, os trabalhos publicados tratam, isoladamente, de tópicos muito específicos que compõem o assunto, e não do produto como um 
todo, de maneira prática e facilmente adaptável à realidade do pão francês no Brasil.

Este trabalho teve como objetivo apresentar uma revisão sobre o assunto, numa tentativa de responder às perguntas mais freqüentes, feitas principalmente por pequenos empresários do setor de panificação, interessados na produção deste tipo de pão, que teriam, para isso, de adaptar a tecnologia já existente.

\section{FORMULAÇÃO}

\subsection{FARINHA DE TRIGO}

Segundo AUTRAN (2) é recomendado o uso de farinhas de trigo com conteúdo protéico entre 10,5 e $12,0 \%$ para a produção do pão francês convencional. Por outro lado, para a formulação de massa congelada, é necessário que se tenha farinha com proteínas de boa qualidade e com teor protéico superior ao usado na produção convencional de pão $(11,17$, $18,21,23,32)$. O teor de proteínas das farinhas de trigo para a produção de massa congelada para pão francês deve estar entre 11 e $13 \%(23,25)$, não devendo ultrapassar $13 \%$ para não restringir seu volume (23). A quantidade e a qualidade das proteínas da farinha é muito importante na produção da massa congelada, uma vez que a mesma é submetida a condições adversas antes da etapa final de assamento $(2,32)$. WANG \& PONTE JR. (32) ressaltam que, nos Estados Unidos, a mudança da qualidade da farinha a cada safra constitui-se num desafio aos produtores de massa congelada, que precisam manter a qualidade do produto toda vez que se inicia um novo lote de farinha proveniente de nova safra.

De acordo com INOUE \& $\operatorname{BUSHUK}(17,18)$ a qualidade da massa congelada está mais relacionada com a força da farinha, do que com a perda de atividade das leveduras durante 0 armazenamento sob congelamento. Tais pesquisadores, após análise no extensógrafo, recomendaram o uso de farinhas com alta resistência à extensão e baixa extensibilidade, capazes de manter bom desenvolvimento do volume do pão durante o assamento, mesmo perdendo parte de sua força intrínseca depois de submetida ao congelamento e ao descongelamento. INOUE \& BUSHUK (17) encontraram correlação positiva altamente significativa entre a resistência máxima no extensógrafo e o volume do pão. Ressaltam que a qualidade da proteína é mais importante que a quantidade, e que a farinha considerada muito forte para a produção de massa convencional deve ser adequada para massa congelada. Na prática, farinha adequada para a produção de massa congelada pode ser obtida pela adição de agentes oxidantes (ácido ascórbico e bromato de potássio) ou de glúten. Por outro lado, RÄSÄNEN et al. (27) trabalhando com massas parcialmente fermentadas antes do congelamento constataram que, a qualidade da 
massa congelada depende mais das condições de processo do que da farinha usada.

O conteúdo de amido danificado não deve ser elevado nas farinhas destinadas à produção de massa congelada (23), as quais devem apresentar baixa concentração de enzimas (como $\alpha$ e $\beta$-amilase), não sendo recomendável a adição de enzimas termo-estáveis de malte (12, 25).

\subsection{LEVEDURA}

Para BRUINSMA \& GIESENSCHLAG (5) a levedura é um dos ingredientes mais importantes na produção de massa congelada e, com certeza, o mais estudado. Recomenda-se a utilização de quantidade de levedura superior à empregada no processo convencional $(15,21,23,25)$, que pode variar entre 4 e 6,5\%. A quantidade necessária de levedura depende do tempo de armazenamento da massa congelada, da formulação e do tempo de fermentação desejado após o descongelamento da massa.

A estabilidade da massa congelada (ou seja, a capacidade da massa em manter inalteradas suas propriedades de viscoelasticidade durante 0 congelamento) e a boa performance da levedura após o descongelamento dependem da qualidade da mesma, sendo recomendável o uso de leveduras com conteúdo protéico superior a 57\% (15). NEYRENEUF \& VAN DER PLAAT (25) recomendam, para a massa congelada de pão francês, $6 \%$ de levedura prensada, o que não traz efeito negativo ao sabor do pão produzido. A levedura deve ser incorporada ao final da etapa de mistura para minimizar a produção de gás antes do congelamento e melhorar sua estabilidade durante o armazenamento sob congelamento.

A tolerância da levedura ao processo de congelamento da massa apresenta grande variação em função das amostras comercialmente disponíveis e requer controle de qualidade apurado, já que, usualmente, a qualidade da levedura está diretamente relacionada ao seu frescor (9). 0 armazenamento prévio da levedura a $4{ }^{\circ} \mathrm{C}$, por três semanas, não afeta sua tolerância aos ciclos de congelamento/descongelamento da massa (10). Já os resultados obtidos por HSU et al. (15) parecem indicar que o armazenamento da levedura sob refrigeração protege as células dos danos causados pelo congelamento, melhorando sua tolerância aos ciclos de congelamento/descongelamento, no caso da massa ser fermentada antes da etapa de congelamento.

Os efeitos do congelamento sobre a levedura dispersa na massa são diferentes daqueles observados quando se faz o congelamento direto da levedura $(7,15,17,19,33)$. A capacidade da levedura em produzir dióxido de carbono é pouco afetada quando a mesma é submetida a sucessivos 
ciclos de congelamento/descongelamento, sendo que os efeitos adversos observados estão relacionados às mudanças das propriedades de viscoelasticidade da massa (5). Já NEYRENEUF \& VAN DER PLAAT (25) constataram que a resistência não é mantida quando as células de levedura estão dispersas na massa, particularmente quando estas, durante o processo, são submetidas a condições desfavoráveis antes do congelamento, resultando em massa enfraquecida. Conseqüentemente, tempos de fermentação mais longos são necessários e, depois do forneamento, resultam em pães com volumes menores.

De acordo com INOUE et al. (19) a atividade da levedura seria responsável pelas mudanças da qualidade da massa somente durante 0 armazenamento congelado, afetando sua extensibilidade. Nunca devido ao enfraquecimento da mesma quando submetida a repetidos ciclos de congelamento/descongelamento, 0 que poderia ser causado por mecanismos como cristalização de gelo, liberação de dióxido de carbono durante o congelamento ou algum outro fator desconhecido. Segundo a literatura $(7,17,19)$ o enfraquecimento da massa, após o ciclo de congelamento/descongelamento, é postulado como sendo resultado do aumento da concentração de substâncias redutoras lixiviadas das leveduras, que provocam a redução das proteínas do glúten, ou da redistribuição da água, causada pela mudança na capacidade de absorção de água pela farinha. Para AUTIO \& SINDA (1), que estudaram a reologia da massa congelada, as mudanças estruturais observadas em massas submetidas ao ciclo de congelamento/descongelamento não estão associadas à liberação de substâncias redutoras por parte das células de levedura, confirmando os resultados obtidos por WOLT \& D'APPOLONIA (33), que associaram estas mudanças ao enfraquecimento da rede de gluten.

MERIC et al. (24), em seus estudos, afirmaram que a resistência aos ciclos de congelamento/descongelamento e a estabilidade da levedura ao congelamento e ao armazenamento prolongado estão diretamente relacionadas ao conteúdo de trealose, que atua como crio-protetor. Entretanto, alto conteúdo de trealose nem sempre está relacionado com maior crio-resistência, sendo ideal entre 4 e $5 \%$ da massa.

Quanto ao tipo de levedura, tanto a levedura seca instantânea como a prensada funcionam bem em massa congelada $(5,8)$. Segundo NEYRENEUF \& VAN DER PLAAT (25) leveduras secas instantâneas resultam em pães com volumes inferiores aos obtidos com levedura prensada. A levedura seca, não instantânea, deve sempre ser reidratada antes da adição na massa. No caso da levedura instantânea, a reidratação só deve ser feita se a temperatura final da massa for inferior a $16^{\circ} \mathrm{C}(5)$.

VAN DAM \& HILLE (30) sugerem a utilização de leveduras mais resistentes aos ciclos de congelamento/descongelamento, como por 
exemplo as osmo-resistentes, utilizadas em massas com alto conteúdo de açúcar. GÉLINAS et al. (10) sugerem o uso de levedura comercializada na forma líquida que, por apresentar qualidade mais constante entre lotes diferentes, tem aplicação mais facilmente controlada, além de poder ser bombeada, o que representa vantagem para as grandes padarias. HINO et al. (13) trabalharam com leveduras tolerantes ao congelamento e afirmaram que as mesmas não são totalmente satisfatórias, pois exigem que a massa seja preparada sob condições ótimas, o que varia dependendo da formulação a ser processada. NEYRENEUF \& VAN DER PLAAT (25) trabalharam com tipo específico de levedura prensada de "atividade reduzida" (46\% de proteína) e observaram que a mesma contribui para a estabilidade da massa.

HOLMES \& HOSENEY (14) não observaram vantagens na adição de fermento químico (bicarbonato de sódio e sulfato de sódio e alumínio) para a preparação de massa congelada, pois não constataram diminuição no tempo de fermentação e nem aumento de volume nos pães produzidos.

\subsection{OUTROS INGREDIENTES}

Além de se levar em conta as características da farinha e da levedura, estudos envolvendo outros ingredientes da formulação mostram a importância dos mesmos sobre o resultado final. Para a produção de massa congelada, a quantidade de água na formulação deve ser menor (7, $21,27)$. Redução de até $2 \%(27)$ resulta em massa mais elástica, com menor formação de cristais de gelo, diminuindo seus efeitos negativos na qualidade da massa congelada (16). A cristalização de gelo afeta particularmente as proteínas, resultando na diminuição da capacidade da massa em reter gás (8). Embora GÉLINAS et al. (8) reconheçam que a redução da quantidade de água, em pães produzidos a partir de massa convencional, resulta em menor volume dos mesmos, afirmaram que tal medida, ao contrário do que comumente se acredita, não apresenta efeito na estabilidade da massa a ser congelada. Recomenda-se também a adição de açúcar (15) e maiores quantidades de gordura (20, 21, 23).

Segundo NEYRENEUF \& VAN DER PLAAT (25), num dos poucos trabalhos que tratam do uso de massa congelada para a produção de pão francês, a "baguette" é produzida a partir de formulação mais simples do que a utilizada na confecção do pão americano, pois não é permitida a adição de açúcar e gordura. Sob condições apropriadas de temperatura durante a produção, em ausência de açúcar não ocorrerá o início da atividade da levedura antes do congelamento. Da mesma forma, a ausência de gordura deixa de proteger as leveduras durante 0 congelamento. Além disso, na França, apenas alguns poucos aditivos são permitidos. 
WANG \& PONTE JR. (32) demonstraram que o volume do pão e a estrutura do miolo são melhoradas, assim como o período de fermentação é drasticamente reduzido, com a adição de $2 \%$ de glúten vital. Glúten vital é aquele tipo de glúten que não sofreu desnaturação irreversível e, em contato com a água, reidrata-se rapidamente, recuperando sua funcionalidade intrínseca, isto é, sua viscoelasticidade (6). Segundo AUTRAN (2) glúten vital é utilizado para aumentar a força da farinha. Além disso, a adição de glúten resolve o problema de deterioração da qualidade da massa quando esta é submetida a ciclos parciais de congelamento e descongelamento, que podem ocorrer devido ao manuseio inadequado do produto durante sua distribuição e armazenamento (17 e 18). Os resultados obtidos também indicam que farinhas com baixos teores de proteínas e suplementadas com glúten podem substituir farinhas com teores protéicos mais elevados na produção de massa congelada (21). Tal fato é conveniente, uma vez que a qualidade da farinha pode variar a cada lote e a suplementação com glúten constitui-se em maneira prática de se tentar solucionar o problema da qualidade variável da farinha. Segundo CZUCHAJOWSKA \& PASZCZYÑSKA (6) glúten vital úmido interage melhor que o seco com o glúten endógeno de farinhas com baixo teor protéico, promovendo melhores resultados na panificação. $O$ efeito das condições de armazenamento nas propriedades funcionais do glúten depende de sua quantidade na massa e, mais especificamente, da qualidade das proteínas.

Para melhorar o volume dos pães, produzidos a partir de massa congelada, recomenda-se o uso de fosfolipídios que minimizam os danos às leveduras provocados pelo congelamento da massa $(7,22,28)$. Segundo SILVA (28) fosfolipídios que apresentam a capacidade de formar lipossomas, quando submetidos à hidratação e agitação, encapsulam as leveduras, protegendo-as e resultando em pães com melhor volume. A inclusão de emulsificantes, como o diacetil tartarato de monoglicerídio ou estearoil 2-lactil lactato de sódio, melhora consideravelmente o volume, a textura e a qualidade geral do pão produzido a partir de massa congelada $(7,20,21,22,23)$. O estearoil 2-lactil lactato de sódio minimiza a redução do volume e da maciez de pães submetidos ao armazenamento prolongado, melhorando consideravelmente a qualidade de massas, mesmo quando estas foram submetidas a três ciclos de congelamento/ descongelamento, assim como a tolerância das mesmas à variação da qualidade dos ingredientes, como a farinha (7).

Em experimentos com massa congelada, vários pesquisadores que utilizaram ácido ascórbico e bromato de potássio $(4,5,8,9,14,15,17,23)$ constataram que o uso combinado destes é mais eficiente do que o uso isolado do primeiro (17), resultando em pães com melhor qualidade. Porém, deve-se ressaltar que 0 uso de bromato de potássio em panificação é proibido no Brasil. O tratamento da farinha com amilases fúngicas melhora consideravelmente a qualidade das massas em que a 
fermentação é interrompida ou retardada, não se recomendando a adição de enzimas de malte (12).

\section{PREPARAÇÃO DA MASSA}

A qualidade da massa congelada varia com a formulação, assim como com as condições de processo (11). A temperatura ideal a ser alcançada pela massa, depois da mistura, é de $20^{\circ} \mathrm{C}$, evitandose, desta forma, o início do processo de fermentação (25). BERGLUND \& SHELTON (4) substituíram parte da água por gelo moído, com a finalidade de manter a temperatura da massa em torno de $22{ }^{\circ} \mathrm{C}$ após a mistura. GÉLINAS et al. (8) sugerem estocar a farinha e a água em temperatura entre 2 e $4{ }^{\circ} \mathrm{C}$.

De acordo com JACKEL (21) melhores resultados são obtidos quando se usa o método direto, adicionando-se o sal no final da mistura e mantendose a temperatura em torno de $17-18{ }^{\circ} \mathrm{C}$ durante o processo, até o completo desenvolvimento da massa. Assim, o método direto, por produzir massa mais densa, que é mais facilmente resfriada e congelada, diminuiria o tempo de exposição das leveduras em condições que estimulam a sua atividade biológica (23). VAN DAM \& HILLE (29) recomendam que a massa seja desenvolvida por mistura (desenvolvimento mecânico) a $15^{\circ} \mathrm{C}$. Segundo outros autores, a massa deve ser completamente desenvolvida na mistura, mantendo-se a temperatura relativamente baixa $(21,25,29)$, porém na presença de agentes oxidantes de ação rápida (23). No método esponja ocorrem danos à levedura durante o final da etapa de mistura, ou seja, quando a esponja é misturada com os demais ingredientes, conforme constatado por HSU et al. (15).

\section{FERMENTAÇÃO}

Segundo vários pesquisadores a atividade da levedura deve ser evitada antes do congelamento $(8,10,13,15,17,21,23,25,30)$, o que otimizaria a produção de gás na massa depois do descongelamento. Deve-se evitar que a levedura seja ativada, pois os maiores danos à levedura ativada seriam provocados pelos produtos da própria fermentação. A melhor estabilidade ao congelamento da massa não fermentada é atribuída às condições relativamente dormentes da levedura.

HOLMES \& HOSENEY (14) observaram que, depois do descongelamento da massa, o volume dos pães submetidos à fermentação a temperaturas inferiores a $32{ }^{\circ} \mathrm{C}$ foram superiores aos fermentados a $43{ }^{\circ} \mathrm{C}$, mesmo que 0 tempo de fermentação tenha diminuído com o aumento da temperatura. Segundo BERGLUND et al. (3) o tempo de fermentação prolongado de massas congeladas, assim como o baixo volume dos pães produzidos são decorrentes de mudanças na ultra-estrutura do glúten e dos grânulos de 
amido, provocadas pela redistribuição de água que ocorre durante o armazenamento sob congelamento prolongado, e pelos ciclos parciais de congelamento e de descongelamento.

De acordo com os estudos de MERIC et al. (24) a pré-fermentação da massa por uma ou duas horas não afeta a resistência das leveduras aos ciclos de congelamento/descongelamento, não ocorrendo o mesmo em relação à estabilidade das mesmas durante armazenamento prolongado da massa. RÄSÄNEN et al. (26), ao estudarem a pré-fermentação da massa antes do congelamento, observaram que a perda de volume dos pães dependia da duração da pré-fermentação, sendo praticamente independente da qualidade da farinha. O benefício da pré-fermentação seria devido à formação de uma rede de glúten mais densa ao redor de maior número de bolhas de ar de menor volume. No entanto, quando interrompida, a pré-fermentação não reduz o problema da perda de volume durante $o$ armazenamento prolongado.

\section{CONGELAMENTO}

Depois da levedura, a velocidade de congelamento constitui-se no parâmetro mais estudado em massas congeladas (8). Obviamente, a velocidade de congelamento e descongelamento dependerá do tipo de congelador utilizado (mecânico ou criogênico), do tipo, do tamanho e do formato do pão, da formulação empregada, etc. Devido à escassez de publicações a respeito de pão francês, os dados apresentados na literatura referem-se aos mais variados tipos de pães, produzidos a partir de diversas formulações, diferentes processos de panificação, com diferentes tamanhos e formatos. Além da temperatura e velocidade de congelamento, há também diferentes recomendações quanto a temperatura de armazenamento da massa congelada. Desta forma, torna-se difícil chegar ao consenso sobre as melhores condições de processamento que devem ser empregadas durante a produção de pão a partir de massa congelada.

O congelamento lento, entre 1 e $3{ }^{\circ} \mathrm{C} / \mathrm{min}$, não afeta a performance da massa depois do descongelamento, garantindo alta taxa de sobrevivência das leveduras (8). HSU et al. (16) também são favoráveis ao congelamento lento, embora considerem mais importante, para a sobrevivência das leveduras, a diferença entre a temperatura mínima alcançada na massa durante o processo de congelamento e a temperatura de armazenamento do produto congelado, do que a velocidade de congelamento propriamente dita. Além disso, os danos às leveduras aumentam com o aumento do período de armazenamento da massa. Assim, recomendam 0 armazenamento da massa, depois de submetida ao congelamento, em temperatura superior $\left(-18^{\circ} \mathrm{C}\right)$ à utilizada para o congelamento da mesma $\left(-34^{\circ} \mathrm{C}\right)$. Segundo tais autores, as células da levedura congelam por volta 
de $-35{ }^{\circ} \mathrm{C}$ e, portanto, temperaturas inferiores a esta devem ser evitadas, pois resultariam em massa congelada de baixa qualidade. Tais condições estão próximas às utilizadas por NEYRENEUF \& VAN DER PLAAT (25) na produção de pão francês: congelamento a $-34{ }^{\circ} \mathrm{C}$, com taxa de congelamento de $1{ }^{\circ} \mathrm{C} /$ min e armazenamento a- $-20^{\circ} \mathrm{C}$.

Massas congeladas produzidas com levedura e processo adequado são estáveis por, no mínimo, três meses. Dependendo do congelador e das condições de congelamento utilizados, este prazo pode alcançar de seis a nove meses $(21,25)$. O conteúdo de água na massa não provoca mudanças na taxa de resfriamento, nem na estabilidade da mesma depois de descongelada, independentemente da forma ou do período de armazenamento (8).

\section{DESCONGELAMENTO E FORNEAMENTO}

No decorrer do descongelamento, as leveduras desidratadas durante 0 congelamento são reidratadas. Segundo HOLMES \& HOSENEY (14) a levedura é menos danificada quando esta reidratação ocorre em temperaturas mais elevadas. Assim, recomendam o descongelamento da massa a $38{ }^{\circ} \mathrm{C}$ e umidade relativa de $9095 \%$. Obviamente, a velocidade de descongelamento também dependerá do tipo, do tamanho e do formato do pão, da formulação empregada e outros fatores, sendo recomendável temperaturas entre $26^{\circ} \mathrm{C}(15)$ a $40{ }^{\circ} \mathrm{C}(5)$, com a umidade relativa variando de 80 a $100 \%$.

BRUINSMA \& GIESENSCHLAG (5) constataram que, se massas congeladas forem remodeladas, mesmo depois de submetidas a vários ciclos de congelamento/descongelamento, resultarão em pães com qualidade satisfatória. Também demonstraram que uma única passagem da massa no cilindro, após o descongelamento, melhora a qualidade da mesma. Já segundo HINO et al. (13) a estrutura da massa, danificada durante os ciclos de congelamento/descongelamento, pode ser recuperada se a mesma for submetida ao boleamento e moldagem depois do descongelamento. De acordo com GÉLINAS et al. (8) as condições de cilindragem de massas não modeladas antes do congelamento não apresentam efeito significativo na taxa de congelamento e, conseqüentemente, na estabilidade das mesmas, não sendo vantajoso retrabalhar a massa várias vezes depois de descongelada (8).

No forneamento, além do tipo, do formato e do tamanho dos pães, a temperatura e o tempo de assamento dependem do tipo de forno (convencional ou turbo) e da carga a ser trabalhada no mesmo. Para pão francês de $350 \mathrm{~g}$ (tipo "baguete") NEYRENEUF et al. (25) utilizaram $225^{\circ} \mathrm{C}$ por 25 minutos. 
Apesar de se encontrar extensa bibliografia a respeito da produção de pão a partir de massa congelada, os trabalhos publicados tratam de massas destinadas à produção dos mais variados formatos, tamanhos e tipos de pães, sendo raramente específicos para pão francês. Estes trabalhos estudam, isoladamente, os vários tópicos que compõem o assunto e não o produto como um todo, de maneira prática e que possibilite a adaptação da tecnologia existente à realidade do pão francês produzido no Brasil. Assim, tendo como base a literatura disponível, torna-se difícil o esclarecimento de algumas questões, como: o congelamento criogênico é melhor do que o mecânico?; a fermentação da massa deve ser realizada antes ou depois da etapa de congelamento?; quais as melhores condições de congelamento e de descongelamento?, evidenciando a necessidade de amplo e detalhado estudo a respeito do assunto.

\begin{abstract}
This paper reviews the use of frozen dough in bread production. The several steps of the breadmaking process for this sort of product are surveyed, from choosing a suitable flour to the baking conditions in the oven, and others such as formulation, mixing conditions of dough, fermentation, freezing and thawing. It concludes that it is very difficult to answer to the most common questions about the subject, relative to the best freezing conditions for dough (mechanic or cryogenic), to the fermentation (prior or after freezing) and to the proper freezing and thawing conditions (fast or slow), once the literature available on the subject deals with different types of dough used to produce several types of breads, and never studies the process as a whole, which difficult the adaptation of the existing technology to the production of frozen French bread in Brazil.
\end{abstract}

\title{
REFERÊNCIAS BIBLIOGRÁFICAS
}

1 AUTIO, K., SINDA, E. Frozen doughs: rheological changes and yeast viability. Cereal Chemistry, St. Paul, v. 69, n. 4, p. 409-413, 1992.

AUTRAN, J.C. Soft Wheat: view from France. Cereal Foods World, St. Paul, v. 34, n. 9, p. 667-676, 1989.

BERGLUND, P.T., SHELTON, D.R., FREEMAN, T.P. Frozen bread dough ultra-structure as affected by duration of frozen storage and freeze-thaw cycles. Cereal Chemistry, St. Paul, v. 68, n. 1, p. 105-107, 1991.

4 BERGLUND, P.T., SHELTON, D.R. Effect of frozen storage duration on firming properties of breads baked from frozen doughs. Cereal Foods World, St. Paul, v. 38, n. 2, p. 89-90,92-93, 1993. 
BRUINSMA, B.L., GIESENSCHLAG, J. Frozen dough performance. Compressed yeast - instant dry yeast. Bakers' Digest, Kansas, v. 58, n. 6, p. 6-7,11, 1984.

6 CZUCHAJOWSKA, Z.; PASZCZYÑSKA, B Is wet gluten good for baking? Cereal Chemistry, St. Paul, v. 73, n. 4, p. 483-489, 1996.

7 DAVIS, E.W. Shelf-life studies on frozen doughs. Bakers' Digest, Kansas, v. 55, n. 3, p. 12,13,16, 1981.

8 GÉLINAS, P., DEAUDELIN, I., GRENIER, M. Frozen dough: effects of dough shape, water content, and sheeting-molding conditions. Cereal Foods World, St. Paul, v. 40, n. 3, p. 124-126, 1995.

9 GÉLINAS, P., LAGIMONIÈRE, M., DUBORD, C. Baker's yeast sampling and frozen dough stability. Cereal Chemistry, St. Paul, v. 70, n. 2, p. 219-225, 1993.

10 GÉLINAS, P., LAGIMONIÈRE, M., RODRIGUE, N. Performance of cream or compressed yeast in frozen and nonfrozen doughs. Cereal Chemistry, St. Paul, v. 71, n. 2, p. 183-186, 1994.

11 GÉLINAS, P., McKINNON, C.M., LUKOW, O.M., TOWNLEY-SMITH, F. Rapid evaluation of frozen and fresh doughs involving stress conditions. Cereal Chemistry, St. Paul, v. 73, n. 6, p. 767-769, 1996.

12 HIMMELSTEIN, A. Enzyme treatment of flour. Will it help frozen and retarded doughs? Bakers' Digest, Kansas, v. 58, n. 5, p. 8,11-12, 1984.

13 HINO, A., TAKANO, H., TANAKA, Y. New freeze-tolerant yeast for frozen dough preparations. Cereal Chemistry, St. Paul, v. 64, n. 4, p. 269-275, 1987.

14 HOLMES, J.T., HOSENEY, R.C. Frozen doughs: freezing and thawing rates and the potential of using a combination of yeast and chemical leavening. Cereal Chemistry, St. Paul, v. 64, n. 4, p. 348-351, 1987.

15 HSU, K.H., HOSENEY, R.C., SEIB, P.A. Frozen dough. I. Factors affecting stability of yeasted doughs. Cereal Chemistry, St. Paul, v. 56, n. 5 , p. $419-424,1979$.

16 HSU, K.H., HOSENEY, R.C., SEIB, P.A. Frozen dough. II. Effects of freezing and storing conditions on the stability of yeasted doughs.

Cereal Chemistry, St. Paul, v. 56, n. 5, p. 424-426, 1979b. 
17 INOUE, Y., BUSHUK, W. Studies on frozen doughs. I. Effects of frozen storage and freeze-thaw cycles on baking and rheological properties. Cereal Chemistry, St. Paul, v. 68, n. 6, p. 627-631, 1991.

18 INOUE, Y., BUSHUK, W. Studies on frozen doughs. II. Flour quality requirements for bread production from frozen dough. Cereal Chemistry, St. Paul, v. 69, n. 4, p. 423-428, 1992.

19 INOUE, Y., SAPIRSTEIN, H.D., TAKAYANAGI, S., BUSHUK, W. Studies on frozen doughs. III. Factors involved in dough weakening during frozen storage and thaw-freeze cycles. Cereal Chemistry, St. Paul, v. 71, n. 2, p. 118-121, 1994.

20 INOUE, Y., SAPIRSTEIN, H.D., BUSHUK, W. Studies on frozen doughs. IV. Effect of shortening systems on baking and rheological properties. Cereal Chemistry, St. Paul, v. 71, n. 2, p. 221-226, 1995.

21 JACKEL, S.S. Frozen dough opportunities keep heating up. Cereal Foods World, St. Paul, v. 36, n. 6, p. 529, 1991.

22 KNIGHTLY, W.H. Surfactants in baked foods: current practice and future trends. Cereal Foods World, St. Paul, v. 33, n. 5, p. 405412, 1988.

23 MARSTON, P.E. Frozen dough for breadmaking. Bakers' Digest, Kansas, v. 52, n. 5, p. 18-20, 37, 1978.

24 MERIC, L., LAMBERT-GUILOIS, S., NEYRENEUF, O., RICHARDMOLARD, D. Cryoresistance of baker's yeast Saccharomyces cerevisiae in frozen dough: contribution of cellular trehalose. Cereal Chemistry, St. Paul, v. 72, n. 6, p. 609-615, 1995.

25 NEYRENEUF, O., VAN DER PLAAT, J.B. Preparation of frozen French bread dough with improved stability. Cereal Chemistry, St. Paul, v. 68, n. 1, p. 60-66, 1991.

26 RÄSÄNEN, J., HÄRKÖNEN, H., AUTIO, K. Freeze-thaw stability of prefermented frozen lean wheat doughs: effect of flour quality and fermentation time. Cereal Chemistry, St. Paul, v. 72, n. 6, p. 637642, 1995.

27 RÄSÄNEN, J., LAURIKAINEN, T., AUTIO, K. Fermentation stability and pore size distribution of frozen prefermented lean wheat doughs. Cereal Chemistry, St. Paul, v. 74, n. 1, p. 56-62, 1997. 
28 SILVA, R. Phospholipids as natural surfactants for the cereal industry. Cereal Foods World, St. Paul, v. 35, n. 10, p. 10081012, 1990.

29 SLUIMER, Ir.P. Principles of dough retarding. Bakers' Digest, Kansas, v. 55, n. 4, p. 6-8,10, 1981.

30 VAN DAM, H.W., HILLE, J.D.R. Yeast and enzymes in breadmaking. Cereal Foods World, St. Paul, v. 37, n. 3, p. 245-252, 1992.

31 VETTER, J.L. Frozen unbaked bread dough: past, present, future. Cereal Foods World, St. Paul, v. 24, n. 2, p. 42-43, 1979.

32 WANG, Z.J., PONTE JR., J.G. Improving frozen dough qualities with the addition of vital wheat gluten. Cereal Foods World, St. Paul, v. 39, n. 7, p. 500-503, 1994.

33 WOLT, M.J., D'APPOLONIA, B.L. Factors involved in the stability of frozen dough. I. The influence of yeast reducing compounds on frozen-dough stability. Cereal Chemistry, St. Paul, v. 61, n. 3, p. 209-212, 1984. 